\title{
MARINE RADIOCARBON RESERVOIR EFFECT IN THE WESTERN NORTH PACIFIC OBSERVED IN ARCHAEOLOGICAL FAUNA
}

\author{
Minoru Yoneda ${ }^{1,2} \bullet$ Masashi Hirota $^{3} \bullet$ Masao Uchida $^{4} \cdot$ Kazuhiro Uzawa $^{5} \bullet$ Atsushi Tanaka $^{1} \bullet$ \\ Yasuyuki Shibata $^{1} \bullet$ Masatoshi Morita $^{1}$

\begin{abstract}
Faunal remains originating from terrestrial and marine mammals, and belonging to the same archaeological deposits were compared to evaluate the marine radiocarbon reservoir ages around the Hokkaido island, Japan. From five shell middens of different ages from the Jomon period (4900 BP) to the Ainu cultural period (800 BP), 107 animal bone samples were selected for radiocarbon measurements. The apparent age differences between Japanese deer and northern fur seal showed the clear effect of deep-water upwelling in this region. Our data showed relatively stable age differences from 4500 $\mathrm{BP}$ to $800 \mathrm{BP}$, with an estimated $\Delta \mathrm{R}$ values around $380{ }^{14} \mathrm{C}$ yr. Results are consistent with previous estimation based on simulation models and oceanographic properties.
\end{abstract}

\section{INTRODUCTION}

In spite of much effort to evaluate the proper correction for ${ }^{14} \mathrm{C}$ ages on marine material all over the world, the appropriate correction for western part of North Pacific surface water has not yet been established because of the lack of appropriate pre-bomb mollusk shells. Because old deep-sea water originating from the North Atlantic ascends to the surface layer in this region, the ${ }^{14} \mathrm{C}$ level in northwest Pacific surface water should be depleted substantially in comparison with typical worldwide surface waters, which show ${ }^{14} \mathrm{C}$ ages about $400{ }^{14} \mathrm{C}$ yr older than the coeval atmosphere (Stuiver and Braziunas 1993). In fact the depletion in eastern part of North Pacific is clearly observed both in prebomb marine materials and shell-wood pairs (Southon et al. 1990). The main objective of this study was to identify the appropriate correction value for the marine materials in western part of North Pacific. At the same time, historical variation of the reservoir effect, which reflects the past intensity of upwelling, was also to be clarified. The reconstruction of temporal change in marine ${ }^{14} \mathrm{C}$ reservoir effect are quite limited (Southon et al. 1990; Kennett et al. 1997). For example, a fluctuation which might reflect the temporal changes in the upwelling intensity was observed at around $6400 \mathrm{BP}$ in British Columbia (Southon et al. 1990).

The evaluation of reservoir age has been conducted mainly by measuring apparent ${ }^{14} \mathrm{C}$ ages in recent shell samples that were collected alive before 1957, before nuclear bomb testing raised atmospheric ${ }^{14} \mathrm{C}$ levels. Calibration is then done taking into account the effect of fossil fuel burning (Suess effect). However, the lack of proper shell samples for this purpose hampered the evaluation of the reservoir correction value along the Japanese coast. We have found and measured several shells stored in a museum, but the results showed unexpected variability (Yoneda et al. 2000). However, the results from Hokkaido area showed relatively stable and older apparent ${ }^{14} \mathrm{C}$ ages, between 550 $\mathrm{BP}$ and $980 \mathrm{BP}$. In order to confirm our previous evaluation, pairs of terrestrial and marine animal remains, excavated from the same archaeological strata, were analyzed. At the same time, it was possible to investigate the stability and temporal fluctuation in the past ${ }^{14} \mathrm{C}$ ages by analyzing pairs from different periods. We obtained archaeological samples excavated from the coastal area along the Volcano Bay on Hokkaido Island, Japan (Figure 1). In this region, subsistence had been based on gathering and hunting from prehistory to the recent period, and the main hunted fauna include Jap-

\footnotetext{
${ }^{1}$ National Institute for Environmental Studies, Onogawa 16-2, Tsukuba, Ibaraki 305-8506, Japan

${ }^{2}$ Corresponding author. E-mail: myoneda @ nies.go.jp.

${ }^{3}$ Environmental Research Center, Ltd., Saiki 210-4, Tsukuba, Ibaraki 305-0028, Japan

${ }^{4}$ Japan Marine Science and Technology Center, Natsushima-cho 2-15, Yokosuka 237-0061, Japan

${ }^{5}$ Rikkyo University, Nishi-Ikebukuro 3-34-1, Toshima, Tokyo 171-0021, Japan
} 


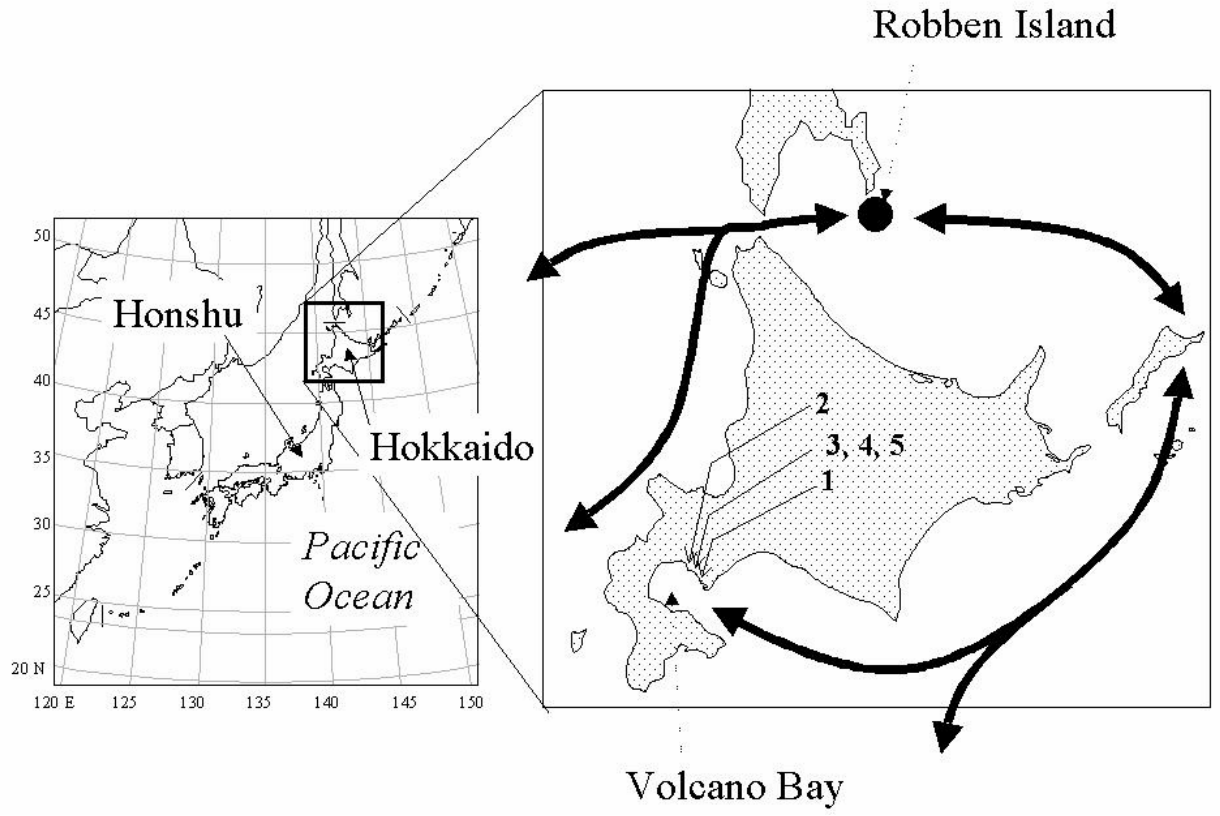

Figure 1 Sampling sites and migration routs of northern fur seal (based on Wada and Itoo, 1999). Sampling sites are indicated by numbers on the map (1: Kitakogane, 2: Takasago, 3: Minami Usu 6, 4: Minami Usu 7, 5: Oyakotsu). Overwinter group observed in the Volcano Bay consists of yearling born on the Robben island and young female seals today (Wada and Itoo 1999).

anese deer (Cervus nippon) and northern fur seal (Callorhinus ursinus). Because these remains have been studied for zoo-archaeology, it was able to select multiple samples from species-identified collections. Multiple measurements were possible to avoid the contamination from different layers by natural agents such as root penetration and/or human activities.

The five archaeological sites analyzed in the present study are located on the coast of the Volcano Bay, southern western Hokkaido (Figure 1). At the Kitakogane shell midden and Takasago shell midden, Jomon cultures were found. Kitakogane produced Ento-kaso type pottery belonging to the Early Jomon culture. The typical age is around 6400-4800 BP. Takasago produced typical objects of the Middle Jomon culture. ${ }^{14} \mathrm{C}$ ages of Early and Middle Jomon periods in Hokkaido have been reported at 6100-4800 BP and 5100-4050 BP respectively (Keally and Mutou, 1982). The Esan culture, the early cultural complex of the Zoku-Jomon period, was found form Minami Usu 6 shell midden. The Minami Usu 7 and Oyakotsu sites contained Satsumon and Ainu cultural objects. In these periods, agriculture was a part of their subsistence as well as hunting, gathering and fishing, but they still created shell middens. It is thought that each periods typically indicate the ages around 20001250 BP for Zoku-Jomon, 1250-600 BP for Satsumon, and from around 600 BP for the Ainu culture. However, no intensive discussion on the absolute ages has not been reported.

In order to calculate the precise age difference between marine and terrestrial animals, it was important to measure samples which were deposited at the same time. Because most faunal remains excavated at these archaeological sites were killed at ages of one or several, we can ignore the problem of long-lived samples, such as wood. However, it was impossible to confirm tight coexistence in deposits for every sample, and every archaeological deposit has some chance of disturbance by human activity and natural agents, although we selected samples excavated from layers which were 
reported as not disturbed. To identify possible intrusive materials, we measured numerous samples from the same layers and assess dispersion in the data sets. Tight grouping of the data sets will give more confidence than data based on measurements on a single pre-bomb shell or a single pair of marine and terrestrial materials.

\section{MATERIALS AND METHODS}

We measured a series of animal bones excavated from the following five archaeological sites located in Hokkaido: Kitakogane site (Early Jomon period), Takasago site (Middle Jomon period), Minami Usu 6 site (Zoku-Jomon period), Minami Usu 7 site (Satsumon period), and Oyakotsu site (Ainu cultural period). Shell midden layers were excavated by archaeologists and we selected the samples for zoo-archaeological analysis and ${ }^{14} \mathrm{C}$ dating. These shell midden sites each contained only a single cultural complex, and are presumed to have been deposited within a short period.

Collagen was extracted from bone by using the improved method of Longin (1971). First, bone fragments of $1 \mathrm{~g}$ were cleaned by brushing and with ultrasound. After removing humic acid and fluvic acid with $0.1 \mathrm{M} \mathrm{NaOH}$, bones were crushed by SPEX freezer mill. $1 \mathrm{M}$ hydrochloric acid was used to dissolve hydroxyapatite, and remaining organic matter was heated at $90^{\circ} \mathrm{C}$ overnight in pure water in order to extract gelatinized collagen. The lyophilized collagen was analyzed for carbon and nitrogen contents to indicate that the extracted materials were collagen and not contaminated by extraneous material. Typically, $0.25 \mathrm{mg}$ of collagen was measured for carbon and nitrogen isotopes simultaneously by using an elemental analyzer and isotope ratio mass spectrometer (EA-IRMS composed of Carlo Erba Instruments NA1500, Finnigan MAT 252, and ConFlo II). The uncertainty with each measurement is estimated as $0.25 \%$ for $\delta^{15} \mathrm{~N}$ and $0.10 \%$ or $\delta^{13} \mathrm{C}$. For the ${ }^{14} \mathrm{C}$ analysis, $2.5 \mathrm{mg}$ collagen was oxidized to $\mathrm{CO}_{2}$ within evacuated tubes and purified with vacuum system cryogenically. Finally, $\mathrm{CO}_{2}$ was reduced to graphite with iron powder catalysis for accelerator mass spectrometry (Kitagawa et al. 1993). Pretreatment and ${ }^{14} \mathrm{C}$ measurements were conducted at NIESTERRA (Tanaka et al. 2000).

\section{RESULTS}

Atomic ratios of carbon and nitrogen showed the values between 3.0 and 3.8. Only three samples from the Minami Usu 7 site were rejected because they exceeded the normal C:N ratio of collagen (2.9-3.6). These three results were excluded in following discussion. However, in general, extracted collagen was preserved very well and extraneous contamination seemed to be quite limited in the case of samples from Hokkaido shell midden. This preservation status was suggested also by stable isotopes. Collagen of seals $\left(\delta^{13} \mathrm{C}:-14.9 \pm 0.6 \%, \delta^{15} \mathrm{~N}: 16.5 \pm 1.4 \% o\right)$ and deer $\left(\delta^{13} \mathrm{C}:-21.9 \pm 0.8 \%\right.$, $\delta^{15} \mathrm{~N}: 3.7 \pm 1.0 \%$ ) indicated clear difference according to their dietary habits.

${ }^{14} \mathrm{C}$ results are shown in Figure 2. It is clear that age differences larger than the worldwide surface ocean average are indicated for all periods from $4900 \mathrm{BP}$ (Kitakogane) to $800 \mathrm{BP}$ (Oyakotsu). However, some layers seemed to contain obvious outliers. Each data set was divided into two or three clusters based on the traditional method (Wilson and Ward 1981). We assumed that the cluster with the largest number of samples should show the most reliable age of the data set (Table 1). In the case of Kitakogane site, we treated four layers containing the same type of pottery as an archaeological assemblage. The calculated ${ }^{14} \mathrm{C}$ age of Kitakogane deer bones is $4913 \pm 14 \mathrm{BP}$, which coincides well with a reported date on charcoal from the Kitakogane; $4800 \pm 140$ BP (N-1094-2: Yamasaki et al. 1977). In sum, the data interpreted as outliers accounted for almost one third of analyzed samples (38 outliers in 104 samples, see Table 1). 


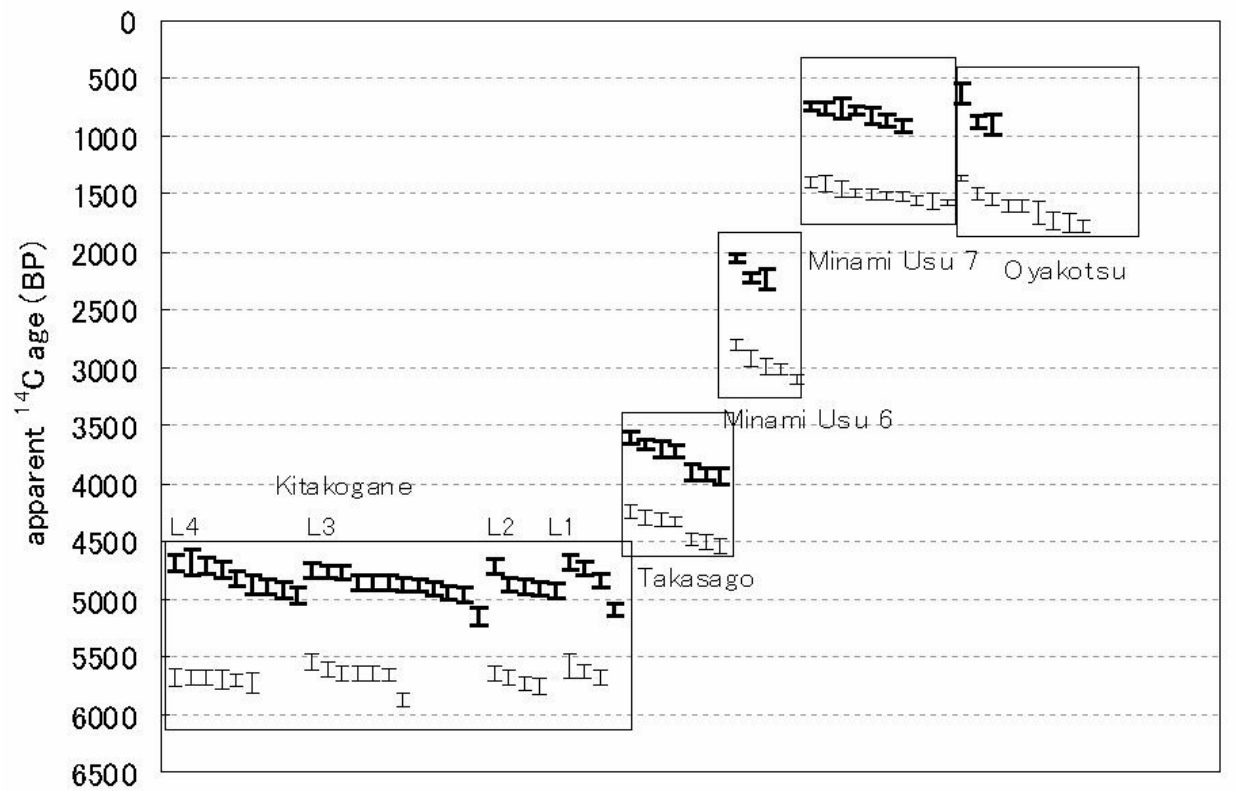

Figure 2 Results of ${ }^{14} \mathrm{C}$ measurement of deer and fur seal bones. Deer bones are illustrated by thick bars and fur seal bones are thin symbols. Each symbol is showing a distribution of each measurement with one standard error of mean. Standard error was calculated based on statistic error with counted number of ${ }^{14} \mathrm{C}$ and standard deviation of repeated measurements. The Kitakogane site includes four layers from the layer 1 (L1: top) to the layer 4 (L4: bottom).

Table 1 Most reliable ${ }^{14} \mathrm{C}$ data sets on deer and fur seal from archaeological sites. In order to estimate the regional correction values ( $\Delta \mathrm{R}$ values), calibrated dates of data sets on deer bones were calculated with atmospheric calibration curve, and then corresponding ${ }^{14} \mathrm{C}$ ages to calibrated years of deer bones on marine material were evaluated on marine calibration curve. The difference between these evaluated ${ }^{14} \mathrm{C}$ age based on deer bones and actually measured ${ }^{14} \mathrm{C}$ ages on seal bones are showing $\Delta \mathrm{R}$ at each period (see Southon et al. 1995).

\begin{tabular}{llccccc} 
Site & Species & $\begin{array}{c}\text { Clustering } \\
\text { sample }\end{array}$ & $\begin{array}{c}\text { Rejected } \\
\text { sample }\end{array}$ & $\begin{array}{c}\text { Pooled } \\
\text { average }\end{array}$ & $\begin{array}{c}\text { Age } \\
\text { difference }\end{array}$ & $\Delta \mathrm{R}$ \\
\hline Kitakogane & Deer & 20 & 10 & $4913 \pm 14$ & $767 \pm 21$ & $392 \pm 22$ \\
(Early Jomon) & Fur seal & 20 & 0 & $5680 \pm 15$ & & \\
Takasago & Deer & 4 & 3 & $3670 \pm 26$ & & \\
(Middle & Fur seal & 4 & 3 & $4297 \pm 33$ & $627 \pm 42$ & $297 \pm 64$ \\
Jomon) & & 2 & 1 & $2228 \pm 21$ & & \\
Minami Usu 6 & Deer & 3 & 2 & $3029 \pm 20$ & & \\
(Zoku-Jomon) & Fur seal & 7 & 3 & $749 \pm 19$ & $740 \pm 66$ & $357 \pm 26$ \\
Minami Usu 7 & Deer & 7 & 3 & $1534 \pm 15$ & & \\
(Satsumon) & Fur seal & 2 & 1 & $882 \pm 47$ & $767 \pm 53$ & $370 \pm 80$ \\
Oyakotsu & Deer & 2 & 2 & $1649 \pm 24$ & & \\
(Ainu) & Fur seal & 7 & & & & \\
\hline
\end{tabular}


Estimated age differences between terrestrial mammals (deer) and marine mammals (fur seal) are shown above in Table 1. Five archaeological sites indicated relatively similar values, around 800 ${ }^{14} \mathrm{C}$ yr, whereas the Takasago site showed slightly smaller age difference of $627 \pm 42{ }^{14} \mathrm{C}$ yr. The reason of this difference will be considered in discussion. Age differences at the other four sites indicate $350-450{ }^{14} \mathrm{C}$ yr as the regional correction values $(\Delta \mathrm{R})$. These four values provide a pooled average of $382 \pm 16{ }^{14} \mathrm{C}$ yr. In further discussion, we assumed that a $\Delta \mathrm{R}$ value of $382{ }^{14} \mathrm{C} \mathrm{yr}$ is representative for the regional correction for ${ }^{14} \mathrm{C}$ marine reservoir effect in the northern part of subpolar front in northwest Pacific.

\section{DISCUSSION}

Live-collected mollusk shells with known years of collection are considered to be the best way to estimate marine reservoir ages because those materials directly record the ${ }^{14} \mathrm{C}$ contents of dissolved inorganic carbon (DIC). In this study, we measured ${ }^{14} \mathrm{C}$ contents in fur seals showing higher $\delta^{15} \mathrm{~N}$ values and a higher trophic level. Although any isotopic fractionation along with food web may have disturbed the reservoir ages originating from DIC in surface water, this phenomena has not been well studied. Olsson (1980) analyzed ${ }^{14} \mathrm{C}$ contents in shells and marine mammals on Swedish and Nordic coasts, which were collected prior to nuclear bomb tests. The reservoir ages were estimated from data on mammals, too, and these agreed with results on shells from the same region. Although this paper does not show the nitrogen isotopic ratios on extracted collagen, seals occupied the highest position in the regional food web. Results indicate that analysis of those higher trophic level samples should be equivalent to evaluation using pre-bomb shells.

Hall (1999) calculated $\Delta \mathrm{R}$ values for Hokkaido and Honshu islands based on comparison between reported ${ }^{14} \mathrm{C}$ ages of wood and shell pairs. Based on the two pairs of data (with large errors) available from Hokkaido, he estimated a larger $\Delta \mathrm{R}$ value and proposed $722 \pm 240{ }^{14} \mathrm{C} \mathrm{yr}$ as preliminary mean value of $\Delta \mathrm{R}$ for Hokkaido. Calculated $\Delta \mathrm{R}$ from a shell-charcoal pair from the Kitakogane site indicated $482 \pm 200{ }^{14} \mathrm{C}$ yr, which corresponds with our results for comparison of deer and seal bones. Although they are not definitive, our results suggest that fur seal, at the highest trophic level, is representative material of ${ }^{14} \mathrm{C}$ activity in surface water.

As pointed out by Southon et al. (1990), the general circulation model predicts very strong depletion of ${ }^{14} \mathrm{C}$ in western part of subpolar front (Troggweiler et al. 1989). However, estimated $\Delta \mathrm{R}$ values in the present study are very similar values to $\Delta \mathrm{R}$ in the eastern North Pacific. GEOSECS data did not show clear differences between western and eastern North Pacific in contemporary ${ }^{14} \mathrm{C}$ activity in surface water (Ostlund and Stuiver 1980), and our $\Delta \mathrm{R}$ estimate of $382{ }^{14} \mathrm{C} \mathrm{yr}$ is virtually identical with the $390 \mathrm{yr}$ value observed on the North American west coast (Stuiver and Braziunas 1993).

We had analyzed a series of pre-bomb mollusk shells collected in western Pacific (Yoneda et al. 2000), which were stored in Kyoto University. Apparent ${ }^{14} \mathrm{C}$ ages were measured on four shells from Hokkaido area; $870 \pm 45 \mathrm{BP}$ (AD 1936), $980 \pm 60 \mathrm{BP}$ (AD 1930), $755 \pm 45 \mathrm{BP}$ (AD 1932), and $520 \pm 55 \mathrm{BP}$ (AD 1932). Although those data do not form a tight group, these old apparent ${ }^{14} \mathrm{C}$ ages correspond to large age differences as observed in this study. In the case of the pre-bomb shell study, sample quality is a crucial factor for accurate estimation, because other kinds of reservoir effects, such as that of ${ }^{14} \mathrm{C}$-depleted fresh water or intake of old organic matters from surrounding sediments, are very difficult to evaluate based on fragmentary information with museum collection.

A much larger fluctuation was observed in pre-bomb shells from the Honshu area (Yoneda et al. 2000). It reflects a complicated oceanographic dynamic from the south to subpolar front. Therefore, evaluation of reservoir correction for other part of Japan will be more difficult and require more 
careful discussion. Ideally, both approaches of marine-terrestrial comparison and pre-bomb shell measurement would be employed, in order to get more information on marine reservoir effect in the region.

Regarding on temporal variability of past upwelling, we can compare our result and a climatic reconstruction based on pollen analyses (Sakaguchi 1989). However, the relationship between $\Delta R$ values and contemporary climate was not significant because all five sites which were analyzed in the present study corresponded to warmer periods. The pollen data showed four cooler periods last 8000 years; at the Middle Jomon (2587 BC-2409 BC), the Latest Jomon (1056BC-580BC), the Kofun (AD 246-AD 732), and the Middle age (AD 1296-AD 1900). For more discussion, we have to analyze more sample sets including those periods in order to reconstruct temporal change in $\Delta R$ values with higher resolution. At the same, the expansion of the time series up to the Younger Dryas event should reveal the role of upwelling for past climate changes.

\section{CONCLUSIONS}

${ }^{14} \mathrm{C}$ ages were measured on terrestrial mammal (deer) and marine mammal (fur seal) excavated from the same archaeological deposits. According to the apparent age differences between these two species, the regional correction value for marine reservoir effect ( $\Delta \mathrm{R}$ values) was calculated at five different periods from $4900 \mathrm{BP}$ to $800 \mathrm{BP}$. The estimated $\Delta \mathrm{R}$ values agreed with each other around a pooled average of $382 \pm 16{ }^{14} \mathrm{C} \mathrm{yr}$, except for the value at $3670 \mathrm{BP}$. This exception might record the fluctuation in the upwelling intensity in this region, but it is likely that the sampling error may play a role. The $\Delta \mathrm{R}$ values proposed here showed good agreement with some oceanographic predictions.

\section{ACKNOWLEDGMENTS}

We wish to thank Prof Y Dodo of Tohoku University, Prof H Ishida of Ryukyu University, and $\mathrm{Mr}$ $\mathrm{H}$ Ohshima of Date City for their kind permission and help in sampling. Dr M E Hall of Niigata Prefectual Museum of History and Prof T Akazawa of International Research Center for Japanese Studies gave us useful comments and suggestions. We acknowledge Ms Y Okabe, Ms Kitazaki, and Ms Y Minoura for assistance, and Dr H Sekiguchi and Mr T Kobayash for AMS operation. Comments from an unknown reviewer were very helpful.

This study was supported in part by Grant-in-aid for Scientific Research (11740481 and 12012225) from the Ministry of Education, Science, Sports and Culture, Japan.

\section{REFERENCES}

Hall ME. 1999. Some archaeological thoughts on AMS dating. In: Proceedings of the International Workshop on Frontiers in Accelerator Mass Spectrometry. National Institute for Environmental Studies and National Museum of Japanese History. p 174-93.

Keally CT, Mutou Y. 1982. Dates of Jomon period. In: Kato S, Kobayashi T, Fujimoto T, editors. Research of Jomon Culture 1. Tokyo: Yuzankaku. p 246-75. In Japanese.

Kennett DJ, Ingram BL, Erlandson JM, Walker P. 1997. Evidence for temporal fluctuations in marine radiocarbon reservoir ages in the Santa Barbara Channel, southern California. Journal of Archaeological Science 24:1051-9.

Kitagawa H, Masuzawa T, Nakamura T, Matsumoto E.
1993. A batch preparation method for graphite targets with low background for AMS ${ }^{14} \mathrm{C}$ measurements. $R a$ diocarbon 35(2):295-300.

Longin R. 1971. New method of collagen extraction for radiocarbon dating. Nature 230:241-2.

Olsson IU. 1980. Content of ${ }^{14} \mathrm{C}$ in marine mammals from north Europe. Radiocarbon 22(3):662-75.

Ostlund HG, Stuiver M. 1980. GEOSECS Pacific radiocarbon. Radiocarbon 22(1):25-53.

Sakaguchi Y. 1989. Some pollen records from Hokkaido and Sakhalin. Bulletin of the Department of Geography University of Tokyo 21:1-17.

Southon JR, Nelson DE, Vogel S. 1990. A record of past ocean-atmosphere radiocarbon differences from the northeast Pacific. Paleoceanography 5(2):197-206. 
Southon JR, Rodman AO, True D. 1995. A comparison of marine and terrestrial radiocarbon ages from northern Chile. Radiocarbon 37(2):389-93.

Stuiver M, Braziunas TF. 1993. Modeling atmospheric ${ }^{14} \mathrm{C}$ and ${ }^{14} \mathrm{C}$ ages of marine samples to $10,000 \mathrm{BC}$. $R a$ diocarbon 35(1):137-89.

Tanaka A, Yoneda M, Uchida M, Uehiro T, Shibata Y, Morita M. 2000. Recent advances in ${ }^{14} \mathrm{C}$ measurement at NIES-TERRA. Nuclear Instruments and Methods in Physical Research B172:107-11.

Toggweiler JR, Dixson K, Bryan K. 1989. Simulations of radiocarbon in a coarse-resolution world ocean model 1. Steady state prebomb distribution. Journal of Geophysical Research 94(C6):8217-42.
Wada K, Itoo T. 1999. Natural History of Pinnipedia. Tokyo: University of Tokyo Press. In Japanese.

Wilson SR, Ward GK. 1981. Evaluation and clustering of radiocarbon age determinations: procedures and paradigms. Archaeometry 23(1):19-39.

Yamasaki F, Hamada C, Hamada T. 1977. RIKEN natural radiocarbon measurements IX. Radiocarbon 19(1): 62-95.

Yoneda M, Kitagawa H, van der Plicht J, Uchida M, Tanaka A, Uehiro T, Shibata Y, Morita M, Ohno T. 2000. Pre-bomb marine reservoir ages in the western North Pacific: preliminary result on Kyoto University collection. Nuclear Instruments and Methods in Physical Research B172:377-81. 